\title{
Atmospheric pollution from ships and its impact on local air quality at a port site in Shanghai
}

\section{Xinning Wang et al.}

Correspondence to: Qingyan Fu (qingyanf@ sheemc.cn) 


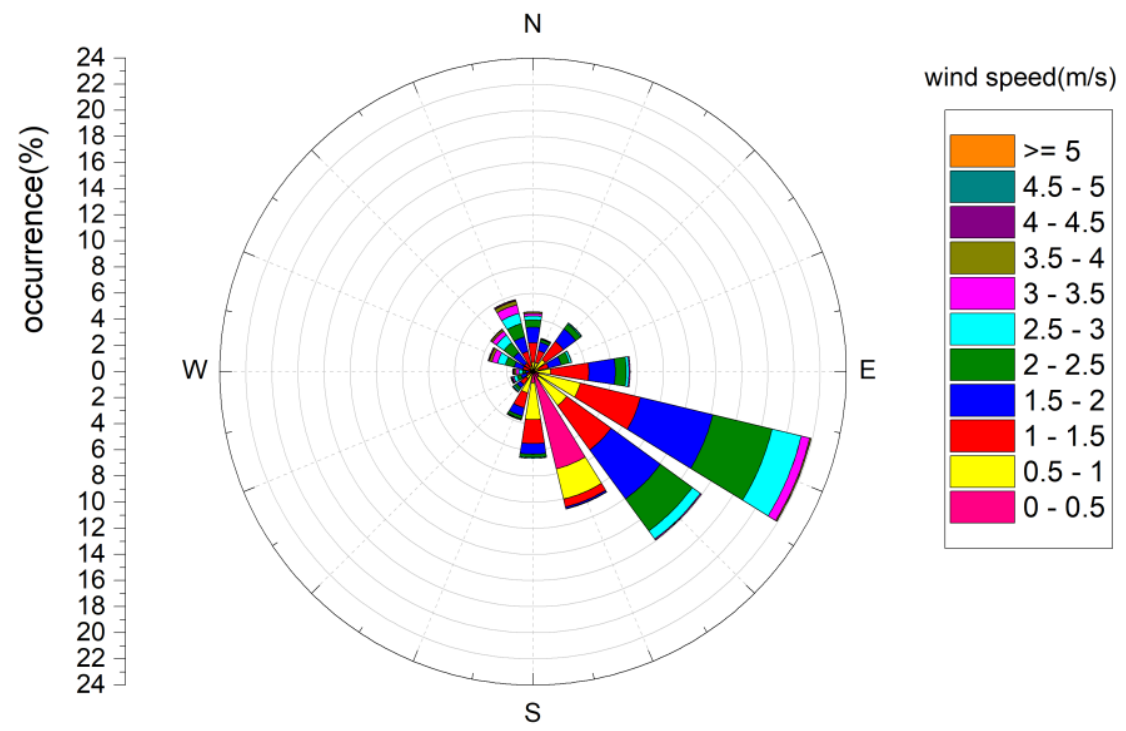

2

Figure S1. Portside wind rose during the study period.

\section{Explanation of identification method of ship emission particles}

The identification method relying on Vanadium signatures left a problem that this method lose some portion of shipping emission particles which produce no or insignificant Vanadium peaks (Xiao et al., 2018). However, within the analyzing capability of SPAMS, Vanadium signatures are still the most reliable indicator of shipping emission particles in a real ambient condition. The present site in port area is both influenced by emission sources from the shipping activities and traffics on land. Single particle signature from diesel vehicles has displayed some similarity with shipping emission (especially for low Sulfur fuel oil, like MGO, IFO) because of the resemblance in chemical composition between them (Toner et al., 2008;Xiao et al., 2018). In this situation, to identify 'true' shipping emission particles from total particles will became difficult or even impossible if we discard the reliable clue of Vanadium. In this supplementary material we illustrate the wind roses of several particle clusters of similar composition with the only major difference of Vanadium (Figure S2). From the figure it is clear that single particles with Vanadium is an ideal indication of shipping emission source from port directions, while the exclusion of Vanadium will only result an unwanted interferences of particles from land sources. Therefore, in present study the online single particle measurement, together with synchronous $\mathrm{SO} 2$ 
1

2

concentration, was utilized to indicate the occurrence of shipping emission plumes, not to dig out every shipping emission particles.
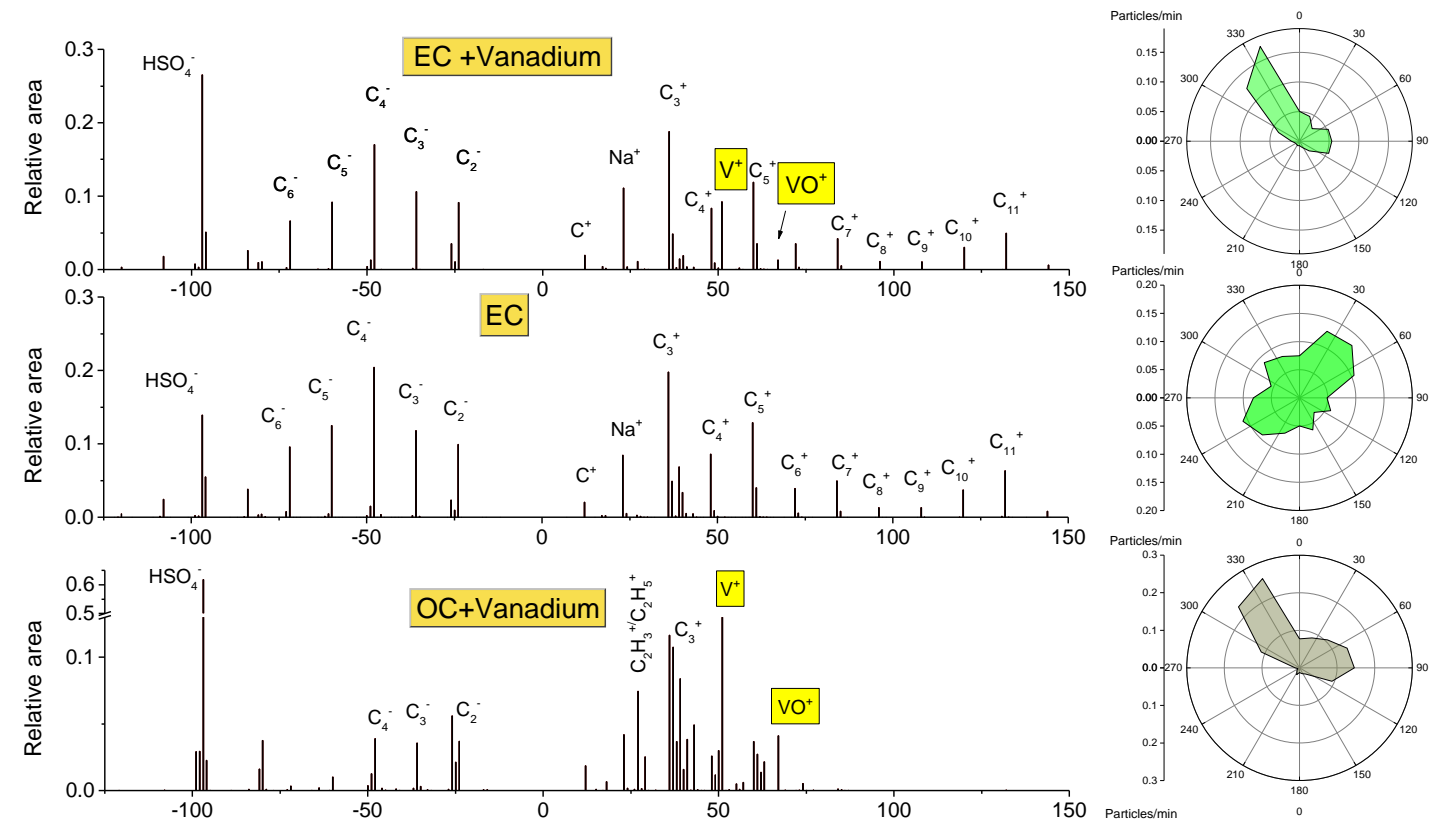

$\mathrm{OC}+$ Vanadium
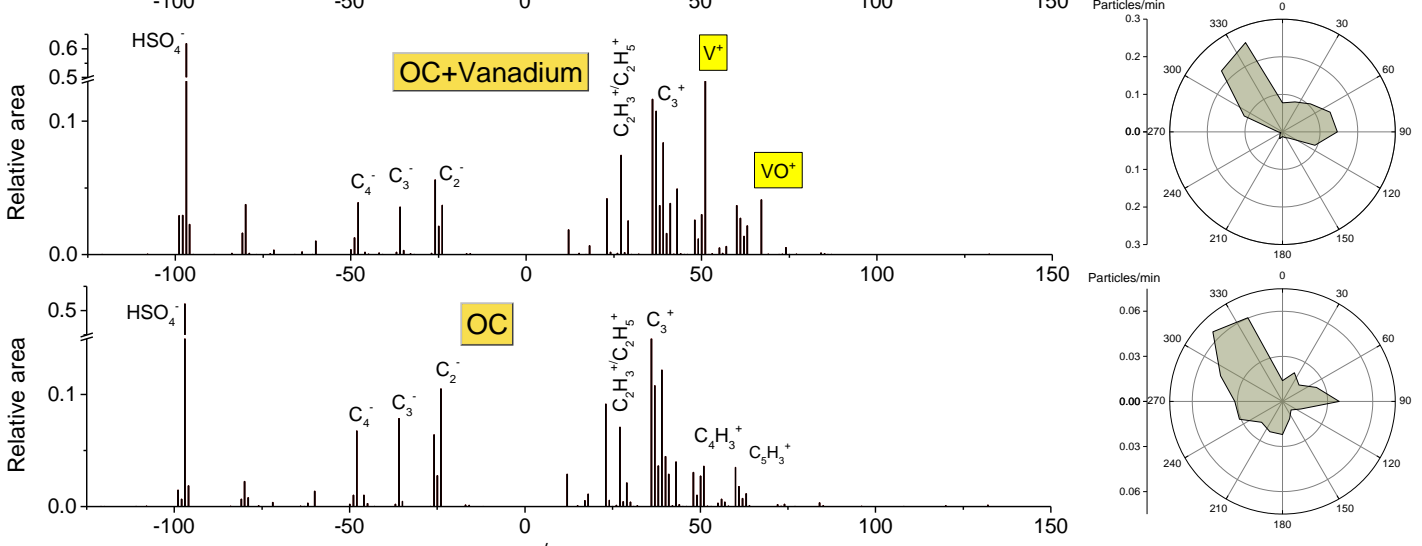

3

4

5

6

7

Figure S2. Mass spectra and wind roses of representative particle clusters with and without vanadium peaks.

3. Temporal variation of $\mathrm{PM}_{2.5}$, vanadium particles, $\mathrm{SO}_{2}$ concentrations in the portside during a period from Jul-03 to Jul-06.

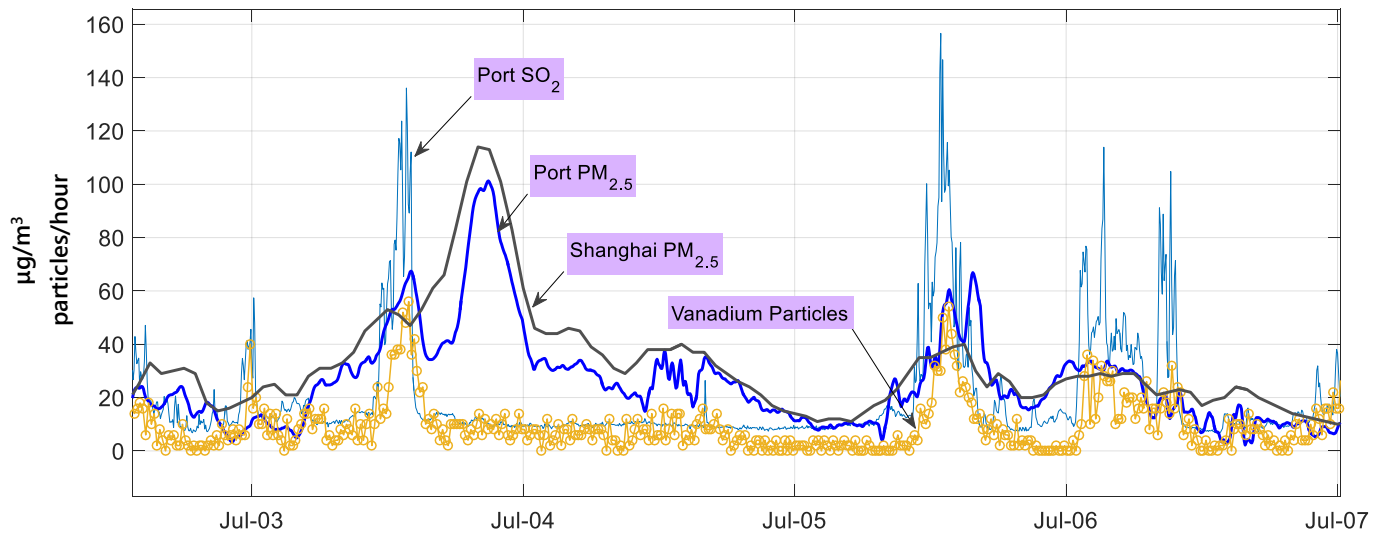

9 Figure $\mathrm{S} 3$. Temporal variations of $\mathrm{SO}_{2}, \mathrm{PM}_{2.5}$, vanadium particles numbers in port site and $\mathrm{PM}_{2.5}$ in Shanghai city from Jul-03 to Jul-06. 


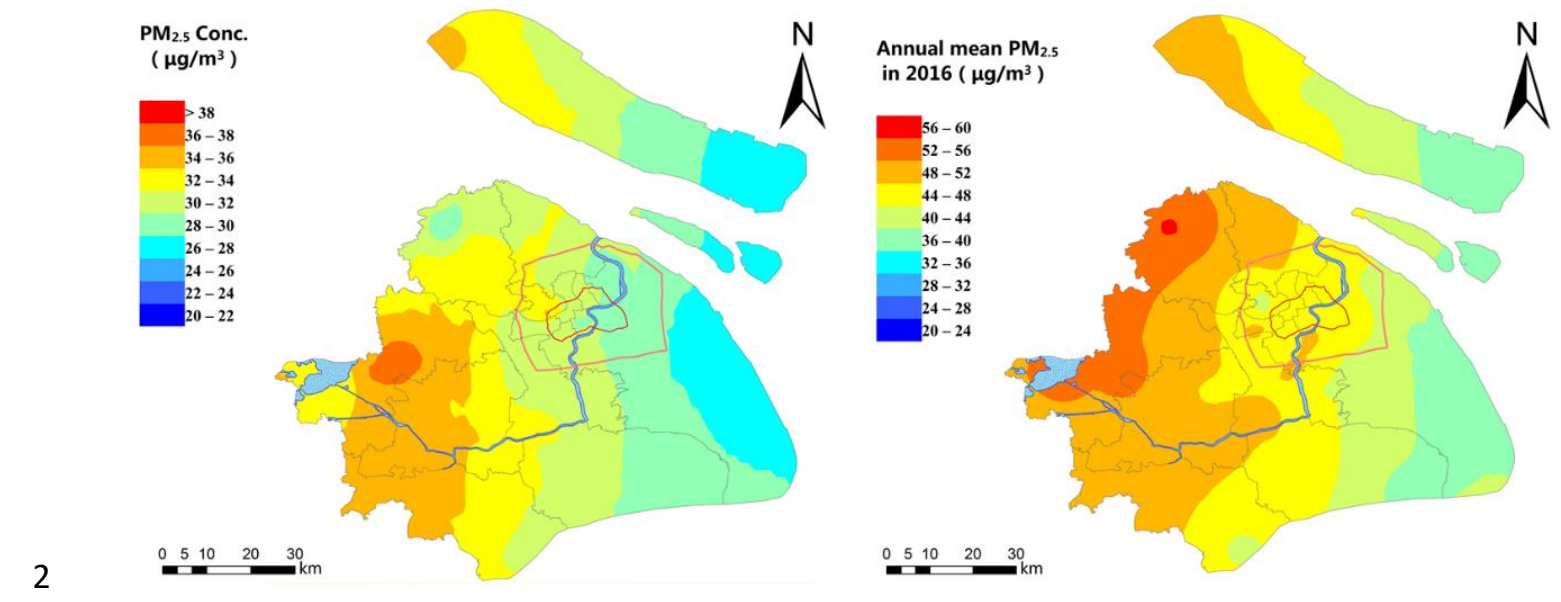

3 Figure S4. Spatial distributions of $\mathrm{PM}_{2.5}$ in Shanghai area in the study period (left) and in 2016 4 (right).

\section{References}

6 Toner, S. M., Shields, L. G., Sodeman, D. A., and Prather, K. A.: Using mass spectral source signatures to

7 apportion exhaust particles from gasoline and diesel powered vehicles in a freeway study using

8 UF-ATOFMS, Atmospheric Environment, 42, 568-581, 10.1016/j.atmosenv.2007.08.005, 2008.

9 Xiao, Q., Li, M., Liu, H., Deng, F., Fu, M., Man, H., Jin, X., Liu, S., Lv, Z., and He, K.: Characteristics of 10 marine shipping emissions at berth: profiles for PM and VOCs, Atmos. Chem. Phys. Discuss., 2018, $1-29,10.5194 /$ acp-2017-1132, 2018 